\title{
Listening to the Urban
}

\author{
Chris A. Wright \\ nb Sheligoe, Willow Mooring \\ London Road, Kegworth \\ Leics. DE74 2EY, UK \\ drcawright@yahoo.com
}

\begin{abstract}
Exploring how aural portraits of urban spaces are perceived, altered, interpreted through the listening process, this paper draws on the discourse between sound and body through the space/time rhythm of urban spaces. In 2017, sound recordings were made at seven everyday sites - café, church, market, station, public transport, high street and shopping centre, in four cities which were, in order of visiting, Leicester, UK; Athens, Greece; Saskatoon, Canada and Cagliari, Sardinia in a methodology that included making alien sound interventions in the field and layering recordings in the studio. This set of recordings, Urban Flows and Non Flows, forms the basis of this paper which focuses on the act of listening, both for artist and subsequent listener. Digital media enables us to listen to sound in our own private spaces, both alone and in public. This brings forth the question of does this create a different listening experience from a shared listening and does this affect its potential meaning? This has an impact on how urban space is heard in the first instance and in later hearings from recordings. The original sites were sites of sonic exchange where one's own presence (due to recording method) is immanent. Does this mean that subsequent listeners of recordings becomes participants and have to reconcile their presence within that hearing or accept that it is inherent within it? Can the territoriality that the original soundscape itself creates be reproduced in the listening process? This work consists of practice-led research, which takes an artistic perspective and draws on a wide-ranging set of influences such as Henri Lefebvre, Murray Schafer, Cláudia Martinho, Brendan LaBelle and Pauline Oliveros.
\end{abstract}

Sound. Art. Urban. Space. Place. Listening.

\section{INTRODUCTION}

Listening to the Urban takes an artist perspective to explore how listening practices perceive, alter and interpret the aural urban environment through the development of my long-term project, Urban Flows and Non-Flows which was begun in 2017. The aim was to explore the discourse between sound and body through the space/time rhythm of urban spaces. Seven everyday sites in four different cities were selected to make sound recordings. These were café, church, market, public transport and relevant station, high street, and shopping centre in Leicester, UK; Athens, Greece, Saskatoon, Canada and Cagliari, Italy, visited in that order. The recordings can be heard online (https://soundcloud.com/chris-a-wright917928995/sets/urban-flows-and-non-flows-1).

In addition to the original recordings, I also attempted to create interventions in the field with varying degrees of success. This was produced by layering one location onto another such as imposing a Leicester café on an Athens café or a Saskatoon church on Cagliari market. The aim of these alien interventions was to investigate the similarities and differences created by usage of space through language and social function. Layerings were also created later in the studio. These sites of sonic exchange collapse inherent flows of spatiotemporal rhythms. A selection of these can be heard in the previous link.

The recordings were made on a Zoom $\mathrm{H} 6$ recorder, for its ease of use in the field and reasonable quality of recording. The recordings were then transferred to a computer where they were lightly edited using the free programme, Audacity. This editing was necessary not to change sound but to remove occasional hisses created by the recording process and tidy up beginnings and endings.

Art installations were created to further try to understand some of the ideas generated by these recordings. The first of these proposed installations consists of a three-part suspended circle with four 
speakers embedded within which play a different set of similarly located recordings in different sequences including periods of silence. The first is Auditour, which used the café audio series.

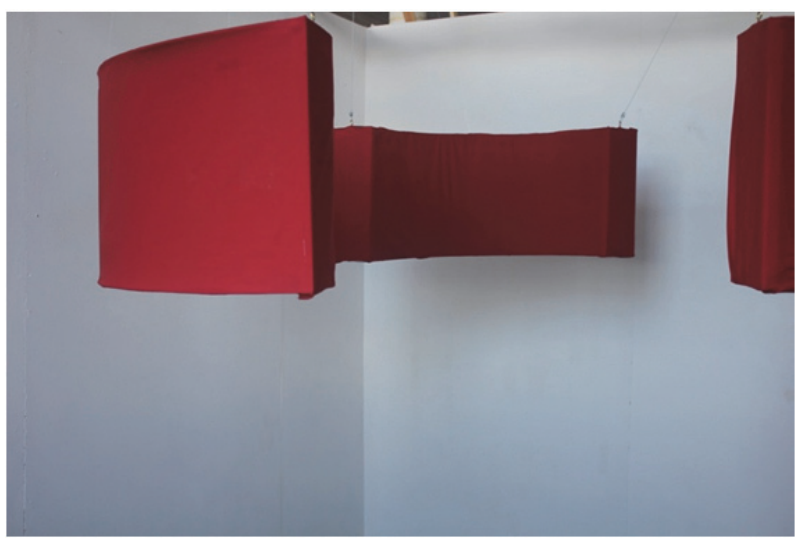

Figure 1: Auditour maquette Café series 2018.

To engage with the work, the listener had to enter the circle. Whilst each speaker could be heard individually by pressing against the speaker, the listeners' trajectory created alternative listening sequences to give a different layering and focus although all four could be heard from the centre. The combinations explored how the listening process perceived, altered and interpreted these recordings. These recordings can be heard online (https://soundcloud.com/chris-a-wright917928995/auditor-series-cafe-culture).

This paper concentrates very particularly on the listening process and asks questions about shared and private listening; location of listening; how is territory perceived when listening to recording as oppose to being in the actual location; does language become meaningless when not understood; how does sound contribute to the action of making place; what does the act of listening to urban space tell us about the space, its function and its users; what does a listener do; can you not listen and how sound is articulated when heard through a recording as oppose to the original event? The first part of this paper, On Listening, explores listening and its relationships whilst the second part, Urban Flow, relates how the sound of the everyday articulates space with reference to place.

\section{ON LISTENING}

Whilst this project began as a way of investigating the sound and rhythms of urban space with regard to social space, architecture and the role of the self, it became obvious that listening was the most important aspect without which the project could not proceed on a meaningful basis. The separation of the position of the artist as both the interlocutor of the space in real time and as recorder, as well as the subsequent manipulator and listener of the recordings, which was then shared with others, was especially relevant. My way of thinking encompasses many disciplines but, essentially, I think of myself as an artist and this perspective pervades my methodology. I am gathering sounds as much as a painter gathers sights that will be later used to and inform the creative process.

Beginning with the real, the actual physicality of being in the urban spaces that I have chosen as my sites, there is no outward distinction between myself and the other users. This initial auditory experience is a shared one. This is a key point as it allows me to be part of the environment and hear in a similar, though not identical way, what others hear when they hear it. Don Ihde writes:

My tape recorder, not having the same intentionality as I, records all these auditory stimuli without distinction (Ihde 2007).

It is not until I listen to the recordings, however, that I realise how much I have missed. The multisensory environment provides too much stimuli and it is only when focussing on the aural element alone, through listening to the recordings later, that this becomes obvious. As Jøran Rudi writes:

\begin{abstract}
Sound envelops us, it invades our personal space; it becomes our personal space. Nearly everything that happens results in or has a sound component, and soundscapes are normally overflowing with all types of information about what is taking place around the listener, be it salient or less important (LaBelle \& Martinho 2011, p.175).
\end{abstract}

We are all enclosed within a sonic space and our perception of that soundscape can be interpreted according to such things as location and personal safety, mood, habits and attention. In the noncontrollable hearing environment such as is the normal everyday experience, this includes things such as traffic, background music, humans such as body sounds, footsteps and mobile phone conversations. A different listening dimension concerns the environment heard through personal listening devices thus the soundscape is mediated through the reception of one's own music via headphones and which I regard as becoming a keynote rather than the surrounding space. Similarly, sharing the aural environment with personal conversations means the space is articulated through the mood generated by those words.

These conversations, meant as private acts become public and part of the shared experience. This is especially true of one-sided mobile phone conversations. Douglas Kahn says: 
When one speaks, the act of hearing one's own voice is the most widespread private act performed in public and the most common public act experienced within the confines of one's own body (Kahn 1999).

The participant in the sonic environment hears not only that but also their presence within it. This is not confined to those deliberately making sounds (people and things) but includes natural body sounds. Thus the presence of self is inherent with the sonic environment and also within the listening process rendering the experience of hearing the aural soundscape as impure due to that presence. However, this personal sonic landscape has always been present within the listener's listening process. My presence is unwittingly participating in and contributing to the aural landscape and I have to reconcile my presence within it not only when part of the original process but in the act of listening to the recordings. Brandon LaBelle writes about German/Canadian composer, Hildegard Westerkamp's work $A$ Walk in the City:

\begin{abstract}
Westerkamp's recordings tell us not only about a city, but about the city captured and composed by the artist. Her sounds reach our ears because of us being there as a presence that while removed nonetheless remains in the recording as an implied personality, however subtle or overt' (LaBelle 2006).
\end{abstract}

Hearing my recordings for the first time, I am immediately aware of this presence. I hear my heartbeat and footsteps, my intakes of breath and my sighs. I realise my presence is doubled in the listening process. I am listening to myself listening. An unconnected listener is listening to their bodies in addition to hearing mine. I become accustomed to these sounds quickly due to their familiarly and accept my complicity within the recordings due to the nature of the process. The rhythms of my body contribute to the rhythms of the cities, which are embedded in the listening. Pauline Oliveros (19322016) includes in her Sonic Mediations with a special procedure for listening which includes 'a reminder to 'listen in the present' as well as 'to remember sounds' and 'a requirement to a willing commitment to the given conditions' (Boon \& Levine 1974). To listen in the present, not to attribute sounds to particular memories, becomes almost an act of disassociation with the self. It does, however, answer the question of what does a listener do. Listening with the full body and mind, what may be called 'attending', creates a different perspective from the general act of listening. Remembering those sounds from within those acts of pure listening contributes to a sense of place and belonging.

Sound researcher and composer, Garth Paine, writes:
The interactive sound environment presents a unique articulation of space and place, one in which the fluidity of the human body can be empowered to find new ways of engaging with environment. This unique and many-faceted approach appoints space itself as a performative medium, instructing the user in new ways of listening, whilst simultaneously casting the listener as performative agent (Bandt, Duffy \& MacKinnon 2007, p.143).

This alters urban space from the impersonal to the personal in real time and interprets the recording space as populated and an implication of place.

\section{URBAN FLOW}

The relevance of space to the act of listening relates closely to notions of place and time through our experience and thus listening becomes a marker of time and space. It implies place, a social space that Henri Lefebvre categorises by its function and its usage. The importance of Lefebvre's work is that it begins to look at space beyond its physical aspects and relates it to the level of the human. My view is that space is activated by the presence of human activity and space and place are fluid and overlap, allowing an ebb and flow of interpretation of the sonic environment.

Focusing on the notion of place, Colin Ripley writes that:

Place in fact comes into being only through sound - through being named by the human voice - and is understood and experiences by humans, not only, but largely by sound (Bandt, Duffy \& MacKinnon 2007, p.89).

This understanding of place shifts focus from eye to ear as a sound environment rather than a purely visual one or, at least, combines two senses to create a multi-layered approach to our way of being in an urban site. Thus the sound of the urban is part of a greater sensory. My recordings isolate the sound at a particular moment in time, take it elsewhere and dislocate it from its source. It is also true that I am not hearing sounds as their true selves, the physics of sound waves in relation to the hearing of them causes distortions in relation to architecture. In essence, what I hear is highly dependant on my location. Barry Blesser and Linda-Ruth Salter in Hearing Events in Space:

Listeners never hear the original sonic event as it was created at the source. As sound waves propagate from the source to the listener, they are always changed during the transport process by the physical acoustics of the environment (Carlyle \& Lane 2013). 
This realisation has to be accepted and ignored for the purposes of the project but which, nevertheless, creates unease during the process of thinking about recording. John Levack Drever in Nostophonics quotes R. Murray Schafer from his notes on the CD The Vancouver Soundscape:

\section{To record sounds is to put a frame round them (Bandt, Duffy \& MacKinnon 2007, p.161; Murray Schafer 1973).}

This frame indicates boundaries and territories, creating a limited act of hearing that is at odds with sound in the wild. Nonetheless, this framing through recording generates a sound event has limitations. For example, it is not enough to compare a café in Athens to one in Saskatoon solely from a single angle. I am not creating a true perspective of the environment.

The intersection of site, sound and body creates a highly personal rendering of the acoustic environment with the site of recording a performative event where I was participating in the activity being recorded. This contributes to the formation of narratives in and around the site, which are fictitious creations that are part of the human necessity to translate and interpret what happens around us. Janet Cardiff writes of her work Münster Walk 1:

Sometimes you fall into a story, but sometimes you have to take steps to unravel it (Beil \& Marí 2008).

The stories that abound in cafes become fragmented in the recordings, they are unravelled in their dislocation form their original site. Cardiff uses walking as a way of understanding site through sound and especially through human sound to create narratives that become specific. LaBelle describes the sound in a café linking it to place and site in Misplace - Dropping Eaves on Ethics. He writes:

\footnotetext{
Within the space of the café, place intrudes or shapes through syntax of necessity, etiquette, and delight - coffee, forks, thank you, and ummmmm - echoing between local situation and the greater shared space created amongst people and how they know one another... speech is always site-specific... The café is hence not simply a backdrop to the whimsy of speech, a kind of soundtrack to the unfolding of the narrative. Rather, place is what in turn produces the narrative; it actively composes the soundtrack, and partially writes the script of social relation. In this regard, the architecture of the cafe is in turn a social architecture, positioning bodies and voices in particular ways, through specific modes of conduct and behaviour (Bandt, Duffy \& MacKinnon 2007, pp.9-10).
}

In the installation, Auditour, the cafés become almost a generalised but still specific environment. The clink of cups can be heard against their saucers, the hiss of the coffee machine and the scrape of chairs are ubiquitous sounds. Within comparisons of sites, volume is an indicator of activity and it is expected in a café at certain times that there will be a particular volume of noise both mechanical and human. It is expected, for example, that churches will be at a lower, more consistent level than a market where the volume fluctuates enormously with shouts punctuating a generalised hubbub as vendors try to lure customers. These become accentuated in recordings and give an indication of function and time of day but not spatial qualities. Justin Bennett in Shotgun Diary 2008-9 asks:

Can one reconstruct the space from a sound recording? (LaBelle \& Martinho 2011).

In Auditour, it is obvious that this space is a café but any other details such as its location where even its country cannot be accurately determined, the size of space, time of day, the smell can only be guessed at. The physicality of being in the café bears little relation to hearing the recordings. The actuality of being in a space activates that space through the presence of self and through its sound in a way that a recording cannot possibly do. The ambiance created by the recording of sound in a space can only be recreated in its hearing through memory and history.

The perception of the consistency of the similarities and differences at each venue due to the function of the locations was, in part, accurate. However, it did not allow for the individuality of national routines and daily rhythms. For example, whilst shopping centres may look very similar internationally, I found that the usage of the centre was time-driven rather than space-driven to a certain extent. This influenced the amount of time a user spent in the location, which reflected on the language used. For example, in a time poor environment, focus was on achieving the aim of a shopping trip. There was a similar aspect to the use of cafes with business conversations taking place at particular times of day rather than general chat.

Creating interventions through interrupting the sonic flow of particular locations through playing alien sounds, whether of a similar site or different, was a form of provocation. These disruptions, which contributed to the idea of non-flows, was a way of trying to perceive a site differently. Whilst the sonic flow within a site was generally inherent to that site, these interventions produced a disharmony that highlighted the function of space and created a confusion of time and space especially during the subsequent listening process. 
These non-flows were an important marker as to the functionality of space. Experimenting with these theories later through manually conflating recordings created a non-space that explored issues of identity. It also commented on the way time is measured and how space, through its move from present to virtual, became a nebulous concept. It was here that listening became the major factor in determining the issues raised.

The issues raised through focussing on listening in an urban space both real and through recording can be seen as especially apparent during subsequent listening. This creates problems for art installations in particular when the isolation of the sense of hearing appears to misrepresent the site, or, at least, shut down a holistic experience of that site. However, this very limitation may open out the narratives, which could be a springboard to greater understanding of space and place through sound. The possibilities are that this could be achieved through digital media in a way not previously available.

\section{CONCLUSION}

This paper draws on an on-going practice-led research project Urban Flows and Non-Flows which utilises sets of recordings made in urban spaces to try and understand how listening alters, perceives and interprets urban space. These recordings are then analysed through different means including interventions and art installations, which are still taking place. The further experimentation is expected to bring broader insights into space and place through this use of sound as well as contributing to my ideas of the shape of sound and ways of display. It was realised that listening was probably the most important aspect of this work, and without which the project would not exist in this form. This paper, Listening to the Urban, therefore, focuses on the act of listening in real time, that is, the artist as sound recorder at the site of recording thus integrating the personal experience of recording into the listening experience and subsequent listening through the medium of sound transmission in whatever form. This includes the artist as well as other listeners. It integrates the personal experience of recording into the listening experience

The project began as an exploration of the discourse of sound through the space/time rhythm of urban spaces but it became obvious that it was a discourse between sound and body through the space/time rhythm of urban spaces. The role of the artist should have been foreseen, however, my approach was a little naïve. I was no longer in an observational role but an inherent part. Thus sound mediated these spaces through and with my presence. The sonic ability of space to accept this, creates different territorial boundaries, and it is these limits that are changed and altered not just through my presence, but also through the inadvertent relationships that are created. Interrupting the status quo through the playing of the alien recordings not only disrupts the known aspects of place but also includes my presence in multiple time. The references become muddled and identity extrapolated even though there was a general common rhythm to each place that was similar to each other place of similar function, not a re-creation but a replay.

Hearing and listening become a dual process that reconciles my inherent presence. The vagaries of hearing are limited by such things as personal aural capacity, extraneous sound, physical properties of site and quality of sound. Hearing is generally an act of the subconscious that Oliveros reminds us to 'listen in the present' to gain maximum benefit. This aspect of listening to the present contributes greatly to my understanding of the project in the holistic sensory experience of making the original footage. This cannot be conveyed through the recordings, but is aimed at through installation, though, not yet successfully. However, it does create an advantage that privileges my listening over that of later listeners. Whilst I am listening to the recordings, I bring all those previous encounters to bear on my understanding of them to create a 'whole' experience. This is the particular reason why ways of display are especially important to me.

Looking to the future, there are digital possibilities that may become available, or affordable, to me, to create recordings more truthfully. These could present new ways of delivering this project as well as better methods of playback thus making listening more accessible.

\section{REFERENCES}

Bandt, R., Duffy, M. and MacKinnon, D. (2007) Hearing Places Sound, Place, Time and Culture. Cambridge Scholars Publishing Newcastle Upon Tyne, UK.

Beil, R., Marí, B. (eds.) (2008) The Killing Machine, Janet Cardiff and George Bures Miller Hatje Cantz Berlin, p.13.

Boon, M. and Levine, G. (eds) Practice, Documents of Contemporary Art. Whitechapel Gallery and MIT Press Cambridge, Massachusetts and London, p.140.

Carlyle, A. and Lane, C. (eds.) (2013) On Listening. Uniform Books Axminster, Devon p.89.

Ihde, D. (2007) Listening and Voice. State University of New York Press New York, p.75. 
Kahn, D. (1999) Noise, Water, Meat. MIT Press Cambridge, Massachusetts and London, p. 7.

LaBelle, B. and Martinho, C. (eds) (2011) Sites of Sound\#2 Of Architecture and the Ear, trans.

Patrick, C. PErrant Bodies Press, Berlin, p.175.
Wright, C. A. (2019) Chris A Wright Soundcloud. https://soundcloud.com/chris-a-wright-917928995 (retrieved 18 March 2019). 